\title{
Climate indicators for forest landing and evaluation of forest shelterbelts
}

\author{
Maftuna Begimova ${ }^{1, *}$ \\ ${ }^{1}$ Tashkent Institute of Irrigation and Agricultural Mechanization Engineers, Faculty of Land \\ Resources Management, 39, Qori Niyazi Street, Tashkent 700000, Uzbekistan
}

\begin{abstract}
Forest shelter belts are one of the effective approaches in the fight against wind erosion, improving the microclimate of fields, protecting roads and reservoirs. The problem of assessing forest plantations and prospects for their creation is relevant for many countries of the world, due to the problem of desertification, water and wind erosion, as well as the global food crisis. The carried out analysis of scientific literature has shown that the existing assessments of forest shelter belts with insufficient degree are being taken into account the modern methods of remote sensing.Therefore, the problem of assessing forest shelterbelts from satellite imagery is relevant.The main part and research results. During the summer period of 2019, in the territory of the protective forest plantations of Fergana Valley of the Republic of Uzbekistan there were laid 170 testing plots. Then 20 test sites, which were used as reference for thematic mapping, there were laid with the collection of additional information: location coordinates and bookmark location. The purpose of the study is to assess the area of forest shelter belts zones of the Republic of Uzbekistan using remote sensing. The object of the study is forest shelter belts of Fergana Valley of the Republic of Uzbekistan.
\end{abstract}

\section{Introduction}

Forest shelterbelts and desert fodder plants are one of the effective approaches in the fight against with wind erosion for livestock feed, improving the microclimate of fields, protecting roads and reservoirs.

The problem of assessing protective forest stands and perspectives of their creation is relevant for many countries of the world, due to the problem of desertification, water and wind erosion, as well as the global food crisis.

The carried out analysis of scientific literature has shown $[1,2,3,4,5]$ that existing assessments of forest shelterbelts and desert fodders are not sufficiently taken into account the modern methods of distance sensing. In particular, the possibilities of remote monitoring of such plots haven't been studied enough. Therefore, the problem of assessing forest shelterbelts from satellite imagery is actual.

* Corresponding author: e-mail: Begimova-1993@mail.ru 
Analysis of the current state of the problem. The climate of Central Asia, including Uzbekistan is determined by the situation in this region, the territory of which is located at a considerable distance from the main sources of moisture - oceans.

Air masses, passing the distance from the Atlantic Ocean to Central Asia, gradually reduce moisture content. Deserts play a certain role in climate formation. In contact with the hot surface of sand, air masses entering to Central Asia are even more dried out. Small reservoirs of the Caspian and Aral seas at very high summer air temperatures do not affect the humidification regime. The flat part of Uzbekistan, unprotected by the mountains and open from the side of the desert is the most arid. Uzbekistan belongs to the Turan climatic province, whose characteristic features are a sharp continental climate, high temperatures and dry air. Large temperature fluctuations are observed both during the year and in the diurnal course. The annual amplitude is $29-30^{\circ} \mathrm{C}$ in the south and $38-40^{\circ} \mathrm{C}$ in the north, daily in the southern regions $18-20^{\circ}$, sometimes much more.[7,8]

The determining factor of climate formation in Central Asia is two centers of atmospheric action: the winter Siberian anticyclone and summer thermal depression (69).

The distribution of precipitation over the territory of the republic depends on the direction of the moist air masses and the surface features of the area. Most of the desert zone is the poorest in precipitation. The average annual amount here is in the range of 80$120 \mathrm{~mm}$ with fluctuations from 40 to $150 \mathrm{~mm}$. As you move to the foothills, the amount of rainfall increases to $400-550 \mathrm{~mm}$, which allows you to grow crops in these areas due to rainfall and the accumulation of moisture in the soil (rainfed farming).

In the regime of precipitation throughout the republic, seasonality of their distribution is pronounced. The greatest amount falls in the spring, slightly less in the fall and winter. March and April are especially rainy, when up to $80 \mathrm{~mm}$ and more can fall in a day. Almost no precipitation occurs in the flat part of the summer.

For Uzbekistan it is characteristic low air humidity: the average annual absolute humidity is 6-8 mb. in winter 11-12 mb. Relative humidity in winter months reaches 70 $80 \%$, in summer months it drops to $25-30 \%$. On some days, it does not exceed $10 \%$.

The plains of Uzbekistan are characterized by high air temperatures: average annual 15$17^{\circ}$. The average air temperatures of the coldest month - January, in most areas range from -: 0.6 to $-6.9^{\circ}$. So, in the lower reaches of the Amu Darya, the average air temperature in January is $-6.9^{\circ} \mathrm{C}$ (Nukus). The sum of negative temperatures is $300-550^{\circ}$. On the Ustyurt plateau $-860^{\circ}$, the absolute minimum is $-38^{\circ}$. The average January temperatures in Termez and Sherabad are $+2.8^{\circ}$ and $+3.6^{\circ}$, the sum of negative temperatures is only -17 $\circ$. The average temperature of the warmest month — July — ranges from 27.1 (Nukus) to $30.1^{\circ}$ (Sherabad).In foothill areas, the average annual air temperature is $2-2.5^{\circ}$ lower than in the lowlands. A characteristic feature of the thermal regime here is the frequency of frosts during transition periods, especially in March.[9,10]

Beyond the republic, the absolute maximum and minimum air temperatures are relatively high. The absolute minimum in Nukus, drops to $-32^{\circ}$, in Termez $-21^{\circ}$. In the foothill zone, the air temperature drops to $-35^{\circ}$. In summer, it continuously increases and in July reaches its maximum values. The absolute maximum in Termez and Sherabad is 44-48 $\circ$. The surface of the soil heats up to $+70^{\circ}$, sand up to $+90^{\circ}$ (167). Such high air temperatures in combination with low humidity and winds cause the occurrence of dry wind phenomena.

Dry climate is also characterized by high evaporation: up to $700 \mathrm{~mm}$ in the north and $1200-1500 \mathrm{~mm}$ in the south of Kyzyl-Kum. Evaporation is an indicator of soil drought (8).

The vegetative period with temperatures above $5^{\circ} \mathrm{C}$ lasts 264 days in Tashkent, up to 321 days in the southern regions (Sherabad), with temperatures above $10^{\circ} \mathrm{C}$ respectively 214-227 days. 
The sum of positive temperatures in the north-eastern part of the republic ranges from +4400 to $+4500^{\circ}$, in the southern (foothills of Surkhandarya) - from $-1-4750$ to $+5100^{\circ}$, in the desert - to $+6000^{\circ}$.

On the territory of Uzbekistan, especially in the flat part, strong wind activity is developed with a predominance of northern, eastern and adjacent wind directions. The occurrence of large storm winds in conditions of narrow gorges and narrow exits from valleys and hollows is due to southern cyclones. Wind activity is especially active in Golodniy Steppe, Kokand group of regions of Ferghana Valley, Bukhara oasis, Karshi steppe and Surkhan-Sherabad valley.[11,12]

In the cold period, north and northeast winds prevail over the territory of Central Asia. Western winds during this period are observed only during the passage of cyclones. The average wind speed ranges from $1.5-2.0 \mathrm{~m} / \mathrm{s}$ in protected oases to $3.5-5.0 \mathrm{~m} / \mathrm{s}$ in the plains of deserts and semi-deserts. In the open areas of the Aral Sea, winds reach 9-10 m/ s.

In the southern deserts and deep valleys, wind activity is activated in the summer, due to the increased atmospheric turbulence.

Mountain elevations, deep depressions and vast valleys cause a peculiar local circulation of the atmosphere. High-speed winds develop mainly at the exits from gorges and pits. A typical example is "Bekabad" wind breaking out of Ferghana Valley. Its maximum speed is $34 \mathrm{~m} / \mathrm{s}$, the highest repeatability is noted in the spring.

In a cold season, as a result of various atmospheric circulations between the northern and southern regions of Central Asia, stormy winds of cold front arise. The orographic anticyclones of the alpine zone also contribute to their formation. Storm winds are widespread in the western part of Ferghana Valley, where the number of days with strong winds exceeds 40-50 per year. Western rumba prevail at a speed of 25-30 m/s.

The local ones also include strong dry winds that occur in the southeastern part of Central Asia, carrying a huge amount of sand and dust, called Afghans. These are westerly winds, reaching 17-20 m/ $\mathrm{s}$ and lasting up to 5 days.

Dry and hot winds are widespread in Central Asia, blowing on the mountain slopes and in the foothill plains of the southern mountain systems- Garmsili are usually of the eastern and southeastern directions, developing speeds of up to $10-15 \mathrm{~m} / \mathrm{s}$ and more. Garmsili, burning plants, cause great damage to agriculture.

In Bukhara oasis, the northern and northwestern winds blowing at a speed of 10-15 m/ $\mathrm{s}$ are most active. In summer, there are usually southerly winds, accompanied by high temperatures. There are more than 30 dry days per year in Bukhara region, in Karshinekiy steppe and Surkhandarya valley- 2 times more.

Analysis of climatic data shows that there are many unfavorable factors in the republic (dry air, high evaporation, strong and hot winds, low water) for the successful cultivation of crops. Years of research and production experience show that these obstacles can be greatly reduced by creating systems of protective forest plantations in the agricultural territory, improving its aesthetic appearance.[13,14,15,16]

\section{The main part and research results}

During summer period of 2018, 170 test plots were laid in the territory of the protective forest plantations of the Ferghana Valley of the Republic of Uzbekistan. 20 test plots, which were then used as reference for thematic mapping, were laid with the collection of additional information: location coordinates and bookmark location. Bookmarking was carried out in forest shelter belts along roads and cultivated agricultural land (Fig. 1). The remaining test sites were collected using high-resolution satellite imagery, cadastral and forest inventory data, and map services.[6] 


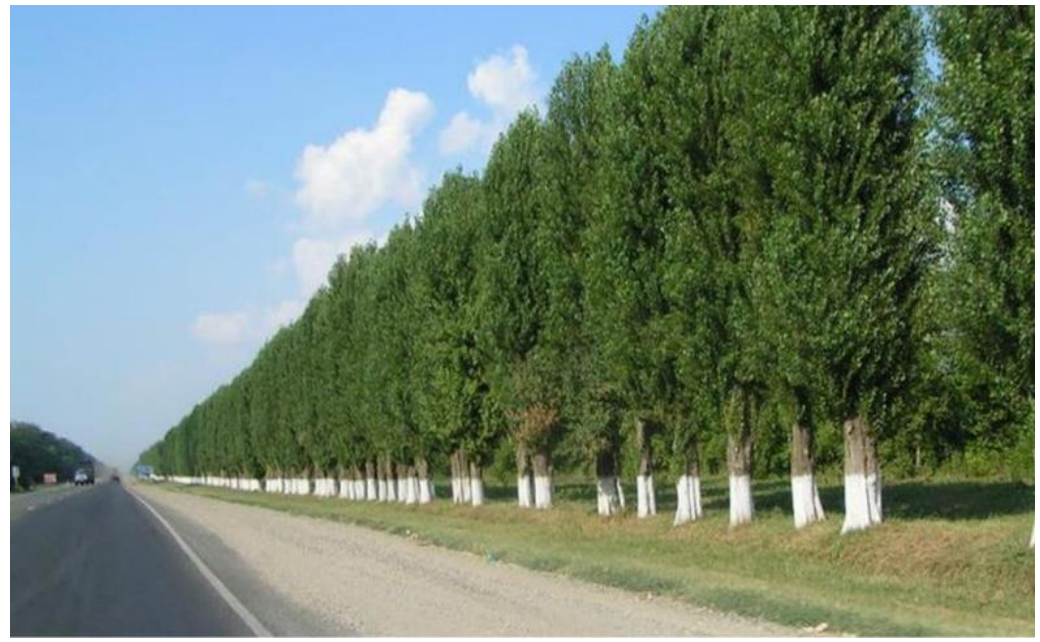

Fig. 1. Caption of the Figure 1. Below the figure.

The coordinates of each test site were recorded using a GPS receiver. The information received was entered to the account sheet a (Table 1).

Table 1. Fragment of the accounting statement.

\begin{tabular}{|c|l|l|c|}
\hline $\begin{array}{r}\text { No } \\
\text { points }\end{array}$ & Location & $\begin{array}{c}\text { Latitude, } \\
\text { des. hail. }\end{array}$ & $\begin{array}{c}\text { Longitude, } \\
\text { des.hail. }\end{array}$ \\
\hline 1 & along the road & 71,0451 & 40,6945 \\
2 & along the field & 71,2825 & 41,0525 \\
3 & along the field & 71,3955 & 40,8939 \\
4 & along the road & 71,4406 & 40,8639 \\
5 & along the road & 71,3184 & 40,6582 \\
6 & along the road & 70,996 & 40,6531 \\
7 & along the field & 70,8867 & 40,5117 \\
8 & along the field & 70,6782 & 40,3831 \\
9 & along the field & 71,1462 & 40,4098 \\
10 & along the road & 71,2454 & 40,4399 \\
11 & along the road & 70,7457 & 40,5851 \\
12 & along the field & 71,4376 & 40,5597 \\
13 & along the road & 71,3184 & 40,6582 \\
14 & along the road & 71,4406 & 40,8639 \\
15 & along the road & 71,3357 & 40,3365 \\
16 & along the road & 70,6782 & 40,3831 \\
17 & along the road & 70,6541 & 40,5678 \\
18 & & 70,7457 & 40,5851 \\
\hline
\end{tabular}




\section{Preparation of satellite data}

For the work, scenes of the high-resolution satellite Sentinel-2 were selected, which covered the study area (Fig. 2).

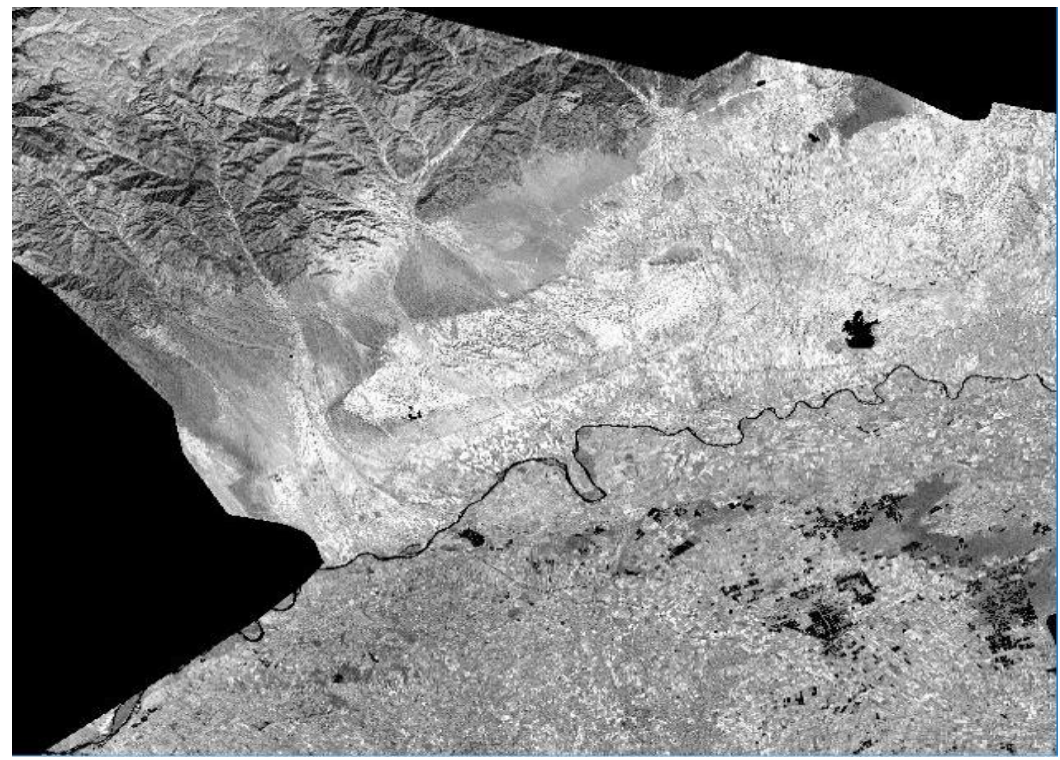

Fig. 2. Scene fragment of the Sentinel-2 satellite used in the study ( date of filming 08/31/2018)

Images selected for the study were prepared for thematic mapping by atmospheric and linear correction, as well as geometric alignment (Fig. 3).
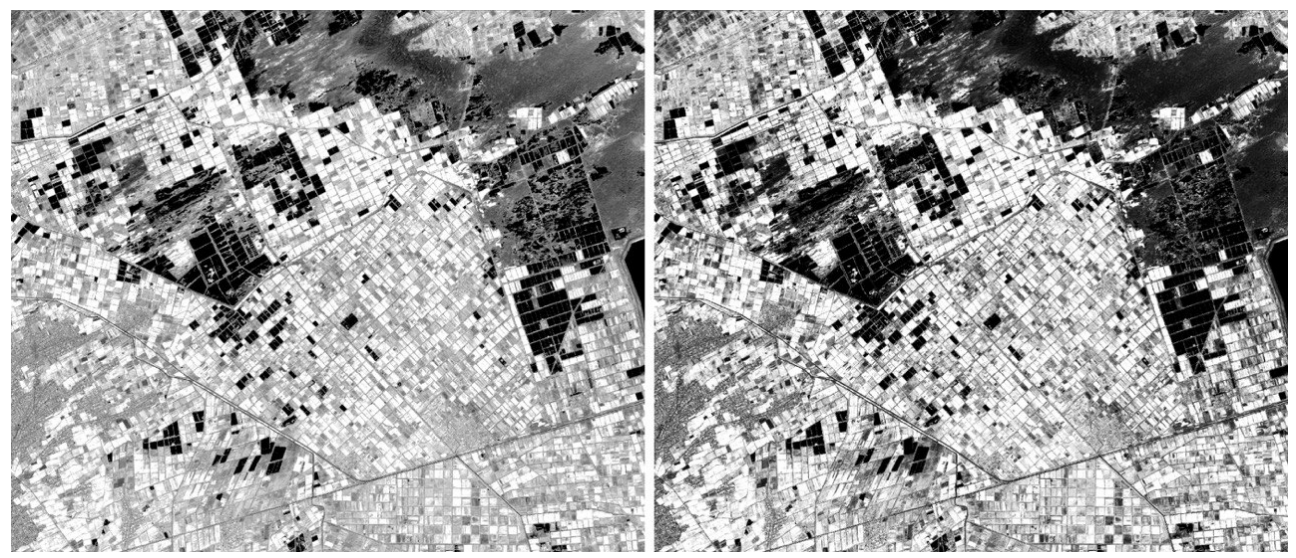

Fig. 3. Sentinel-2 snapshot fragment ( 8 th spectral channel) before (left) and after (right) linear alignment

Selected images were cropped to the mask of Ferghana Valley and sewn into a seamless mosaic for further work (Fig. 4). 


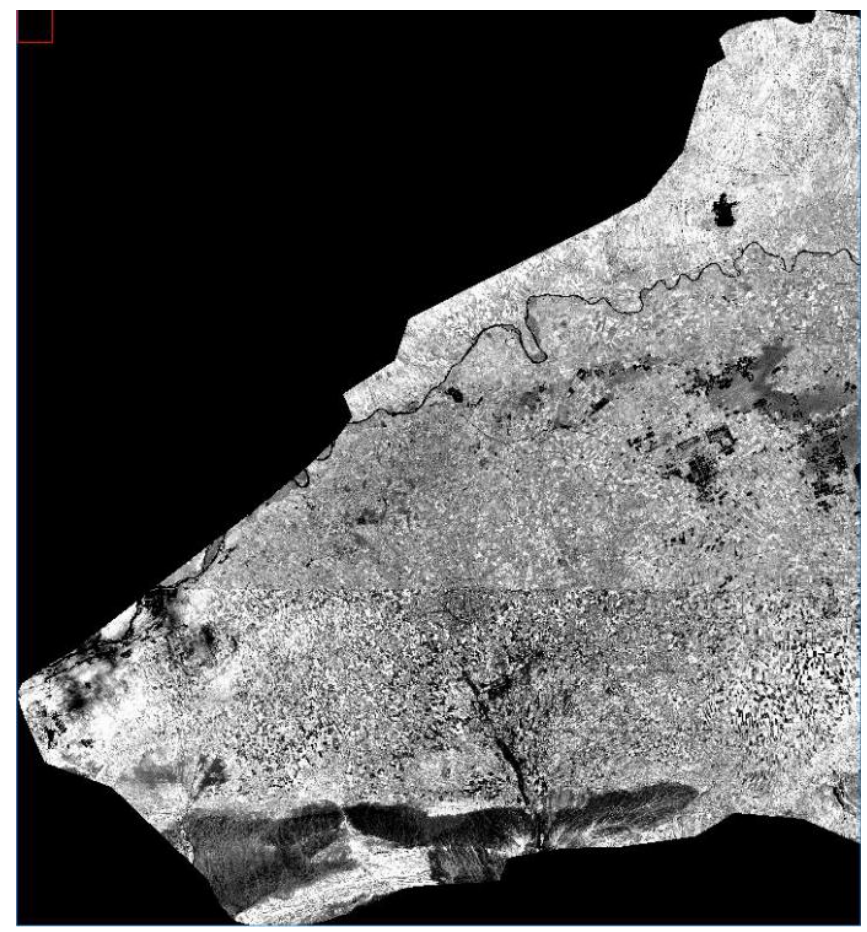

Fig. 4. Seamless mosaic of fragments of satellite images to the study area.

The pledged test sites were highlighted and tied to matched satellite images.

\section{Conclusion and recommendations}

In this article, the author's research results, which are aimed at filling the gaps in the study of monitoring and evaluation of protective forest belts of the Republic of Uzbekistan according to remote sensing data.

The research work includes the results of the author's research, which are aimed at filling the gaps in the study of the tasks of monitoring and assessing the protective forest belts of the Republic of Uzbekistan according to remote sensing data.

The use of the method of separability of vegetation cover classes in high-resolution satellite images of Sentinel-2 is justified by the high accuracy of thematic mapping.

When constructing a thematic map of protective forest plantations of Fergana Valley of the Republic of Uzbekistan, their total area for 2019 was determined. The total area of protective forest bands is just over 27 thousand hectares, which is about $5 \%$ of the territory. This figure is generally consistent with official data, according to which the total area of forest shelter belts as of 2007 was 40 thousand ha.

\section{Reference:}

1. Z. Yu, T. Qin, D. Yan, M. Yan, The impact on the ecosystem services value of the ecological shelter zone reconstruction in the upper reaches the basin of the Yangtze river in China. International Journal of Environmental Research and Public Health. p.15. (2018). 
2. Y. Zhang, Z. Yang, S. Guo, Q. Wang, K. Zhan, Ecological changes in the Minqin oasis belt over the past 20 years. Acta Prataculturae Sinica. P.14-24. (2018).

3. J. Zhengzhong, W. Yingju, L. Jiaqiang, Influence of plantation of a shelter-belt on component of organic carbon in the Taklimakan desert over last decade. E3S Web of Conferences. p.53. (2018)

4. Z. Zuo, Z. Pan, A. Zhang, D. Yu, Z. Zuo, Spatial wind speed and surface wind erosion characteristics of farm-shelter forest nework in arid sandy area. Transactions of the Chinese Society of Agricultural Engineering. P.135-141. (2018).

5. V. Kachova, G. Hinkov, E. Popov, L. Trichkov. Agroforestry in Bulgaria: history, presence status and prospects./ V // Agroforestry Systems P.655-665 (2018).

6. G. Lantzanakis, Z. Mitraka, N. Chrysoulakis, Comparison of Physically and Image Based Atmospheric Correction Methods for Sentinel-2 Satellite Imagery. Perspectives on Atmospheric Sciences P. 255-261. (2016).

7. P. Marcela, P. Marco, S. Andreas, S. Harald, Relationships between forest variables and remote sensing data in a Nothofaguspumilio forest. Journal Geocarto International. P.25-43. (2009)

8. G. Mateo, J. Tomislav, The effect of fusing Sentinel-2 bands on land-cover classification. Johnson International Journal of Remote Sensing. p. 39. (2017)

9. A. Mitchell, B. Mora, Current remote sensing approaches to monitoring forest degradation in suport of countries measurement, reporting and verification (MRV) systems for REDD. Carbon Balance Management P. 9-10. (2017)

10. K. Miyamoto, Decreased Rice Production as the Result of Windbreak-cutting. Journal of Agricultural Meteorology. P.145-148. (1961)

11. R. Nisa, Evaluation of roadside green belt trees damaged by mistletoes parasite plant in Mean Merdeka Road, Central Jakarta, Indonesia. IOP Conference Series: Earthand Environmental Science p.203. (2018)

12. H. Pengyu, L. Fabian, B. Chandrashekhar. Pengyu, Annual Cropland Mapping Using Reference Landsat Time Series A Case Study in Central Asia. Distance Sensing P.1012. (2018)

13. E.P. Da, M. Fleckenstein, P. Leinenkugel, A. Parker, N. Oppelt, C. Kuenzer, Tropical forest cover dynamics for Latin America using Earth observation data: a review covering the continental, regional, and local scale. International Journal of Distance Sensing. Published online. P.3196-3242 (2015).

14. J.W Roberts, S. Tesfamichael, M. Gebreslasie, J. Aardt, Forest structural assessment using remote sensing technologies: an overview of the current state of the art. Southern Hemisphere Forestry Journal. p.69. (2010)

15. E. Romijn, C. B. Lantican, M. Herold, Assessing change in national forest monitoring capacities of 99 tropical contries. Forest Ecology and Management Vol. 352. p. 109123. (2015)

16. N. Yakimov, The value of afforestation afforestation to combat erosion processes on agricultural land. Land of Belarus - (2014). p. 3-7.A. 